\title{
Perancangan Aplikasi Penjualan Furniture Dengan Metode Waterfall Berbasis Web
}

\author{
Hendri $^{1}$, Jefi ${ }^{2}$, Desiana Nur Kholifah ${ }^{3}$, Kusmayanti Solecha ${ }^{4}$, Rio Nugraha Armanda ${ }^{5}$ \\ ${ }^{1}$ Program Studi Teknologi Informatika, Universitas Nusa Mandiri \\ Jl. Jatiwaringin Raya No. 2 Jakarta Timur, 13620, Indonesia \\ ${ }^{2,4}$ Program Studi Teknologi Informasi, Universitas Bina Sarana Informatika \\ J1. Kramat Raya No.98 Jakarta Pusat, 10450, Indonesia \\ ${ }^{3}$ Program Studi Sistem Informasi, Universitas Nusa Mandiri \\ Jl. Jatiwaringin Raya No. 2 Jakarta Timur, 13620, Indonesia \\ ${ }^{5}$ Program Studi Sistem Informasi, Universitas Bina Sarana Informatika \\ Jl. Cut Mutiah No. 88 Bekasi, Indonesia \\ e-mail: hendri.hed@ nusamandiri.ac.id, ${ }^{2}$ jefi.jfi@bsi.ac.id, ${ }^{4}$ kusmayanti.ksc@bsi.ac.id, \\ desiana.dfh@nusamandiri.ac.id, rionugraha25.rn@gmail.com
}

Artikel Info : Diterima : 28-06-2021 | Direvisi : 12-07-2021 $\mid$ Disetujui : 21-07-2021

\begin{abstract}
Abstrak - Saat ini, kemajuan teknologi sangat berkembang begitu pesat sekali, sehingga pekerjaan yang sulit dapat diselesaikan dengan begitu mudah. Banyak dari para pemilik toko furniture yang tokonya ingin sekali banyak diketahui oleh masyarakat luas tetapi sistem penjualan yang digunakan masih dalam bentuk manual. Dengan memanfaatkan perkembangan teknologi, pemilik toko furniture membutuhkan sistem terkomputerisasi. Oleh karena itu, dibutuhkan sebuah aplikasi penjualan furniture berbasis web. Pembuatan program ini dengan metode waterfall. Pembuatan aplikasi ini juga menggunakan framework Codeigniter dengan bahasa pemrograman PHP dan database MySQL, yang memudahkan pelanggan dan pemilik toko dalam mengelola data, informasi toko, memproses transaksi hingga memasarkan furniture secara digital.
\end{abstract}

Kata Kunci : Penjualan Furniture, Codeigniter, PHP

\begin{abstract}
Nowadays, technological advances are growing so rapidly, so that difficult jobs can be completed so easily. Many of the furniture shop owners want their shop to be widely known by the public, but the sales system used is still in manual form. By taking advantage of technological developments, furniture shop owners need a computerized system. Therefore, a web-based furniture sales application is needed. Making this program with the waterfall method. Making this application also uses the Codeigniter framework with the PHP programming language and MYSQL database, which makes it easier for customers and shop owners to manage data, store information, process transactions and market furniture digitally.
\end{abstract}

Keywords : Furniture sales, Codeigniter, PHP

\section{PENDAHULUAN}

Manusia adalah mahluk cerdas yang selalu ingin meningkatkan kemampuannya untuk memudahkan segala kegiatannya. Segala alat dicoba dan digunakan untuk mencapai efisiensi dan efektifitas setiap tindakan yang dilakukannya, berbagai percobaan dilakukan agar dapat menghasilkan efisiensi yang besar dengan tenaga yang seminimal mungkin (Danuri, 2019).

Revolusi industri yaitu perubahan cara hidup dan proses kerja manusia secara fundamental, dimana dengan adanya kemajuan teknologi informasi dapat mengintregrasikan dalam kehidupan dengan digital yang dapat memberikan dampak bagi seluruh disiplin ilmu (Hamdan, 2018).

Menurut pasal 1 ayat 2 UU No. 11 tahun 2008 tentang informasi dan transaksi elektronik, oleh karena itu kegiatan jual beli yang dilakukan melalui komputer atau handphone, dikategorikan sebagai transaksi elektronik. 
Salah satu kemajuan teknologi yang digunakan yakni sebuah sistem informasi berbasis web yang sangat dibutuhkan dalam dunia usaha saat ini (Saryoko, Studi, Komputer, Labu, \& Selatan, 2015).

Membangun rangkaian rancangan dan implementasi dari sistem informasi yang kompleks untuk mengatasi masalah seperti sistem yang digunakan masih manual mulai dari pemesanan barang, perhitungan penjualan, perhitungan stok barang dan pembuatan laporan yang sering kali terjadi masalah dalam keakuratan data dan tentunya akan merugikan waktu dan biaya dalam kegiatan operasional.(Saryoko et al., 2015)(Ermawati, Ichsan, \& Wahyuni, 2018)(Prasetyo \& Susanti, 2016)

Untuk itu diperlukan sebuah sistem informasi berbasis internet terhubung secara online tanpa mengenal batas waktu dan tempat yang dapat mempermudah jalannya suatu transaksi penjualan dan pekerjaan yang ada dapat diselesaikan secara cepat, tepat dan akurat.(Irawan, Rahmalisa, Wahyuni, \& Devis, 2019)(Muhammad \& Kusnadi, 2018) Sekaligus sebagai media promosi dalam penjualan online agar dapat meningkatkan kembali jumlah penjualan dan jumlah pengunjung yang melihat produk furniture.(Ermawati et al., 2018)(Prasetyo \& Susanti, 2016)(Irawan et al., 2019)(Muhammad \& Kusnadi, 2018)(Fandhilah, Pratmanto, \& Fatakhudin, 2015)

Toko Depo furniture diirikan oleh H.Sajidin Edi Gunawan pada awal tahun 2009 yang merupakan sebuah toko yang menjual berbagai macam furniture rumah tangga. Proses penjualan yang dilakukan masih dengan cara konvensional yaitu pelanggan datang ke toko untuk melakukan pemesanan produk furniture. Proses seperti ini dinilai kurang efekrif apabila terus dilakukan hingga jangka panjang, dikarenakan informasi produk yang hanya diketahui oleh pelanggan dikalangan sekitar toko. Sehingga pelanggan diluar kota mengalami kesulitan harus datang ke toko dan bertanya langsung dengam karyawan toko mengenai detail dan harga furniture tersebut. Serta perhitungan penjualan yang belum terkomputerisasi sehingga menyebabkan resiko ketidak akuratan dalam pembuatan laporan.

Oleh karena itu, perlu dibuatkan sistem penjualan furniture berbasis web. Agar toko Depo Furniture dapat mempublikasikan tentang informasi untuk menawarkan produk kepada masyarakat luas khususnya masyarakat diluar kota, Dengan adanya program bisnis berbasis web ini, penjualan produk yang dilakukan secara online dapat memudahkan pelanggan melakukan transaksi dan menghasilkan laporan perhitungan penjualan yang cepat, tepat dan akurat, serta memaksimalkan keuntungan bagi pemilik toko.

Penelitian yang terkait dengan program penjualan telah dilakukan oleh para peneliti sebelumnya dengan menggunakan berbagai metode. Adapun penelitian yang menghasilkan sistem informasi berbasis web sebagai media promosi, pemesanan dan pembelian secara online dengan metode Rapid Application Development (Ermawati et al., 2018).

Penelitian yang lain dilakukan dengan membangun system e-commerce sebagai media penjualan dan promosi produk menggunakan Sistem Informasi dan Teknik Pemodelan (System information engineering and modeling) (Irawan et al., 2019). Hasil dari serangkaian penelitian tersebut menunjukkan bahwa dari sisi performa dan efisiensi, sistem ini sangat membantu dalam menjalankan proses bisnis dibandingkan dengan metode manual. Pada penelitian ini, kami merancang sebuah aplikasi penjualan berbasis web menggunakan metode waterfall.

Perbedaan dengan penelitian sebelumnya adalah kami menggunaan metode waterfall dalam pengembangan system informasi karena metode waterfall bersifat sistematis dan berurutan dalam membangun sebuah perangkat lunak, kemudian persamaan dengan penelitian sebelumnya adalah pembangunan aplikasi yang bertujuan untuk pengelolaan data penjualan dalam sebuah perusahaan.

\section{METODE PENELITIAN}

\section{Pengembangan Sistem}

Penelitian ini dilakukan dengan menggunakan metode waterfall. Model waterfall merupakan salah satu model SDLC yang sering digunakan atau sering disebut juga dengan model konvensional atau classic life cycle (Susanto, R., Andriana, A. D., Susanto, R., \& Andriana, 2016)

Tahapan dalam metode waterfall yaitu : (1) Analisa kebutuhan perangkat lunak. Proses pengumpulan kebutuhan pada tingkatan sistem dengan menentukan konsep kebutuhan website penjualan furniture, membuat pendaftaran untuk calon pelanggan agar mempermudah calon pelanggan dalam melakukan transaksi dan produk dikelompokan dalam beberapa jenis kategori agar mempermudah pelanggan mencari produk yang diinginkan, serta memudahkan admin dalam mengelola data transaksi dan data pelanggan. (2) Desain software merupakan proses perancangan sistem ini dimulai dengan merancang Entity Relationship Diagram (ERD), Logical Record Structure (LRS) dan struktur navigasi. (3) Code Generation mendesain apa saja yang diperlukan dalam pembuatan aplikasi ini menggunakan framework Codeigniter dengan bahasa pemrograman HTML, PHP dan database yang digunakan yaitu MySQL. (4) Testing Pengujian berfokus pada perangkat lunak dari segi logic dan fungsional serta memastikan bahwa semua bagian sudah diuji. Hal ini dilakukan untuk meminimalisir kesalahan (error) dan memastikan keluaran yang dihasilkan sesuai yang diinginkan.

2. Analisa Kebutuhan Software

Dalam tahap analisa kebutuhan para pengguna mempunyai kebutuhan informasi yang berbeda beda. Dalam tahap analisa ini dapat dibagi menjadi dua, yaitu kebutuhan pengguna dan kebutuhan sistem. Tahap analisis 
kebutuhan pengguna pada perancangan ini memiliki dua pengguna yaitu admin dan user. Hasil analisis admin tersebut adalah: a) Data user dan data admin dapat dikelola oleh admin, b) Admin dapat mengelola data produk, kategori dan data kota, c) Admin dapat mengelola data pesanan, d) Admin dapat mencetak laporan, e) Admin dapat memverifikasi pembayaran. Hasil analisis user tersebut adalah: a) User dapat melihat produk furniture, b) User dapat melakukan transaksi pemesanan mulai dari melihat detail pembayaran, mencetak invoice detail pembayaran, melihat riwayat pesanan, mencetak invoce pesanan, melakukan konfirmasi pembayaran, mengupload bukti pembayaran, c) melihat tentang kami, d) dapat melihat kontak, e) dapat melihat social media.

3. Kebutuhan Sistem

Kebutuhan sistem pada perancangan ini terbagi menjadi dua yaitu kebutuhan user dan kebutuhan admin. Hasil analisis kebutuhan user adalah a) User yang ingin membeli diharuskan melakukan pendaftaran akun di halaman register dan melengkapi data pribadi, b) Dihalaman furniture user dapat melihat kategori dan produk yang dijual, serta dapat memilih dan melihat lengkap informasi produk, c) User yang ingin melakukan pembelian dapat klik add to card maka akan otomatis masuk ke kranjang, lalu klik pembayaran maka akan menampilkan form data alamat pengiriman dengan mengisi nama, no telepon, alamat, pilih kota, jasa pengiriman, bank payment, dan pilih selesai belanja, d) Setelah user melakukan pembelian, sistem kan menampilkan halaman invoice dan pelanggan diharuskan melakukan pembayaran. Hasil analisis kebutuhan admin adalah a) Admin harus melakukan login terlebih dahulu agar dapat mengakses atau masuk ke halaman admin, b) Setelah masuk, admin dapat mengelola website sesuai kebutuhan, c) Admin dapat melihat data pesanan, d) Admin dapat mengelola data pesanan dan melakukan verifikasi pembayaran, e) Admin dapat mencetak laporan.

4. Entity Relationship Diagram (ERD)

Menurut Al-Bahar dalam penelitian Rahmayu Entity Relationship Diagram (ERD) yaitu diagram yang menunjukkan informasi dibuat, disimpan, dan digunakan dalam sistem bisnis. Entity Relationship Diagram (ERD) merupakan gambaran data yang dimodelkan dalam suatu diagram yang digunakan untuk mendokumentasikan data dengan cara menentukan apa saja yang terdapat tiap entity dan bagaimana hubungan antara entity satu dengan lainnya.(Rahmayu, 2016)

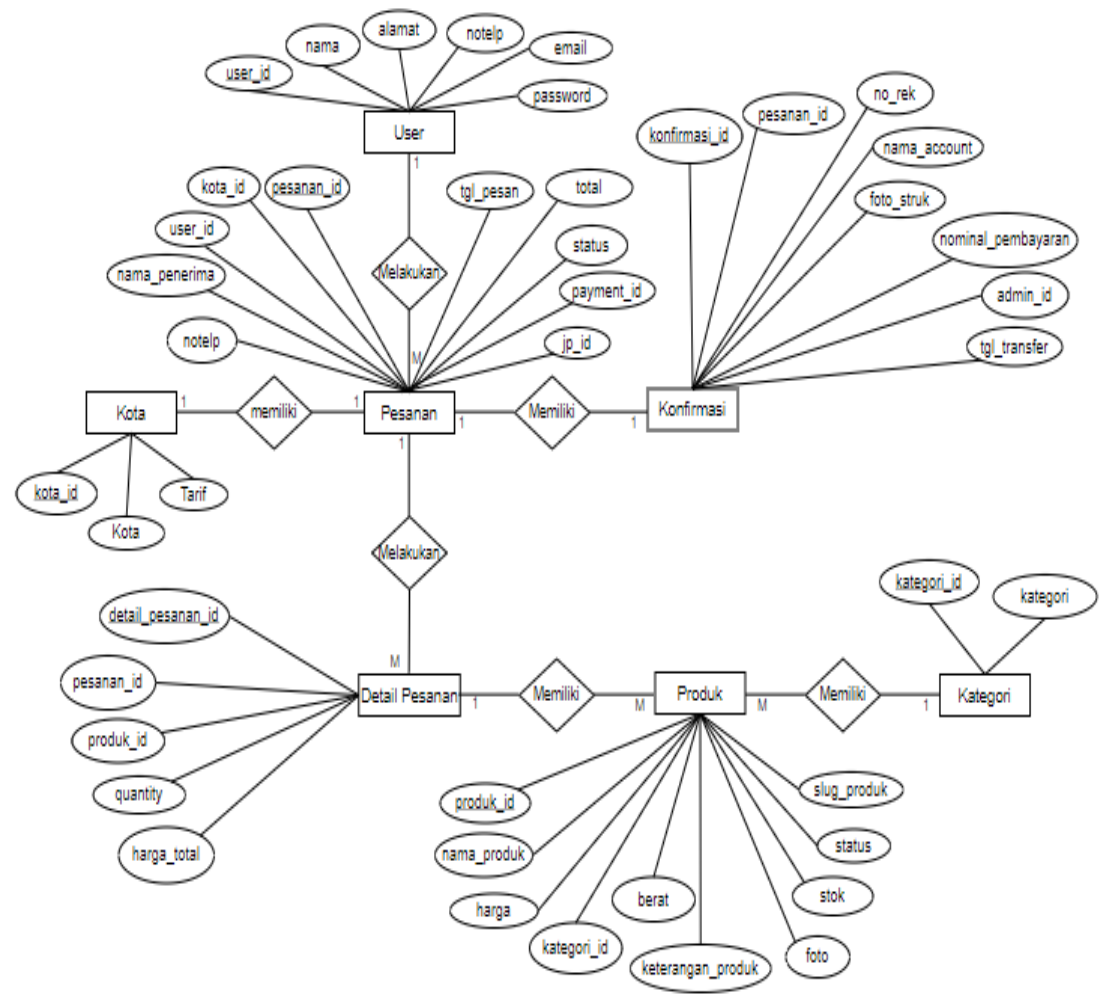

Sumber: Hendri (2021)

Gambar 1. Entity Relationship Diagram Aplikasi Penjualan Furniture Berbasis Web 
Computer Science (CO-SCIENCE)

Volume 1 No. 2 Juli 2021 | E-ISSN: 2774-9711

$5 \quad$ Logical Record Structure (LRS)

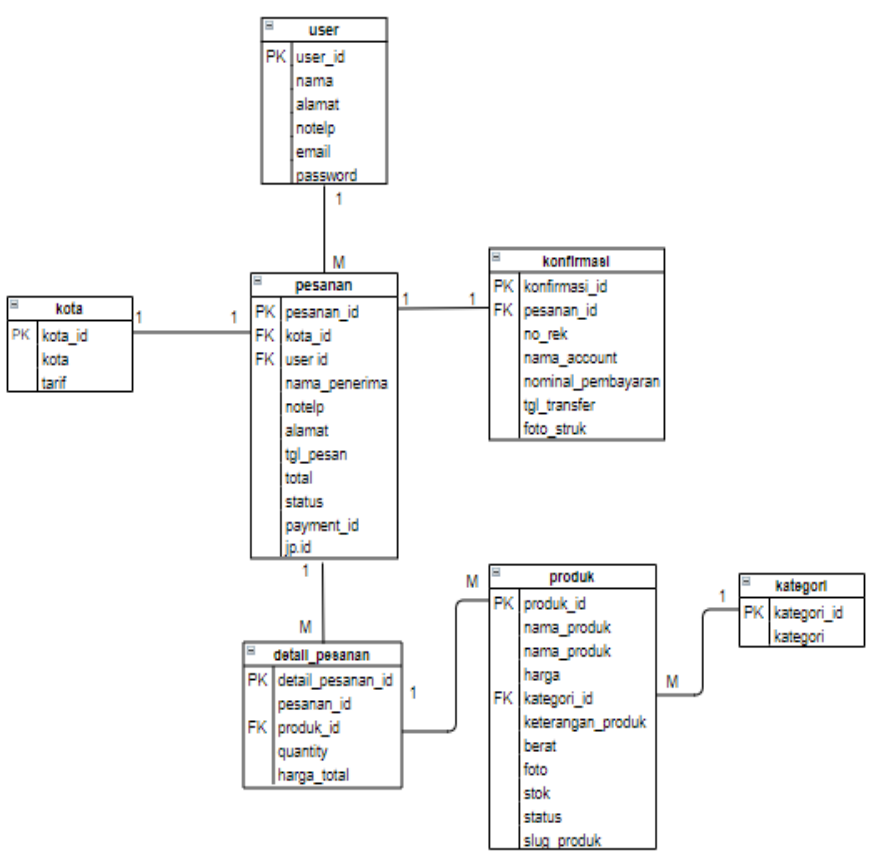

Sumber: Hendri (2021)

Gambar 2. Logical Record Structure Aplikasi Penjualan Furniture Berbasis Web

6 Spesifikasi Program

Struktur navigasi website digunakan untuk memberitahukan kepada pengunjung, pelanggan, atau pihak admin mengenai lokasi-lokasi halaman yang bisa dikunjungi dari tiap-tiap halaman. Struktur navigasi pada website toko furniture menggunakan struktur navogasi capuran (composite) dimana tampilannya nanti bisa diakses secara logis.

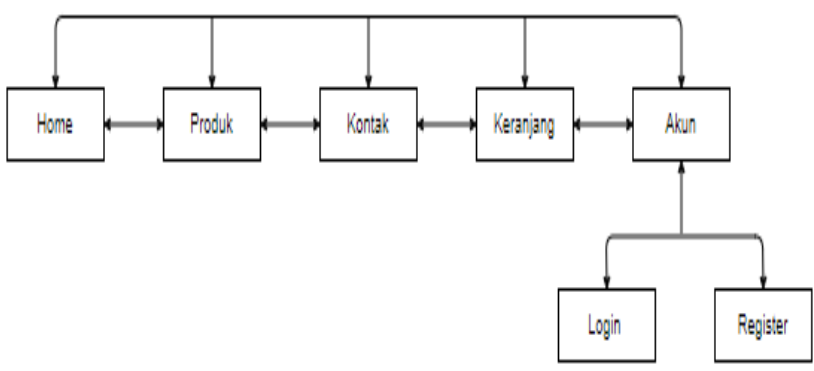

Sumber: Hendri (2021)

Gambar 3. Struktur Navigasi Menu Pengunjung

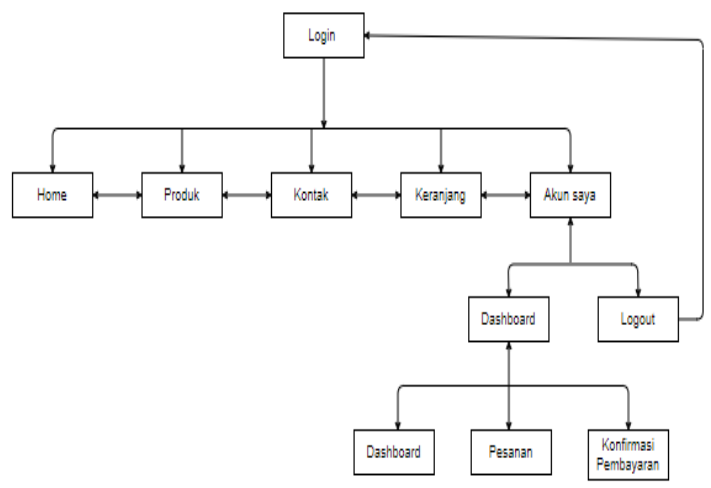

Sumber: Hendri (2021)

Gambar 4. Struktur Navigasi Menu User 
Computer Science (CO-SCIENCE)

Volume 1 No. 2 Juli 2021 | E-ISSN: 2774-9711

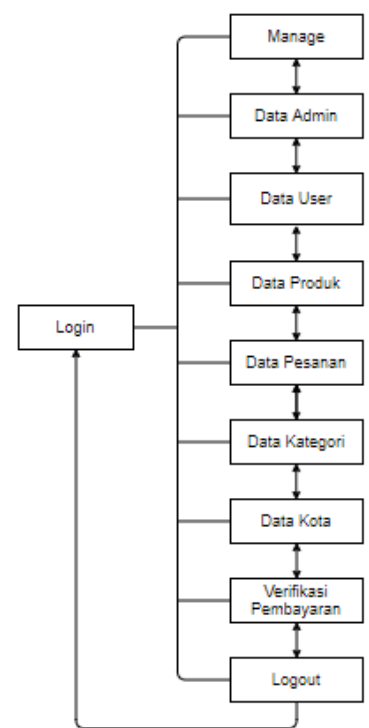

Sumber: Hendri (2021)

Gambar 5. Struktur Navigasi Menu Admin

\section{HASIL DAN PEMBAHASAN}

Aplikasi penjualan furniture memiliki tiga level user yaitu admin dan user. kedua user tersebut memiliki hak akses yang berbeda. Penggunaan aplikasi tersebut dilakukan dengan user harus login dengan mengisi username dan password secara benar.

Untuk mendaftar sebagai user baru, dapat mengakses menu register.

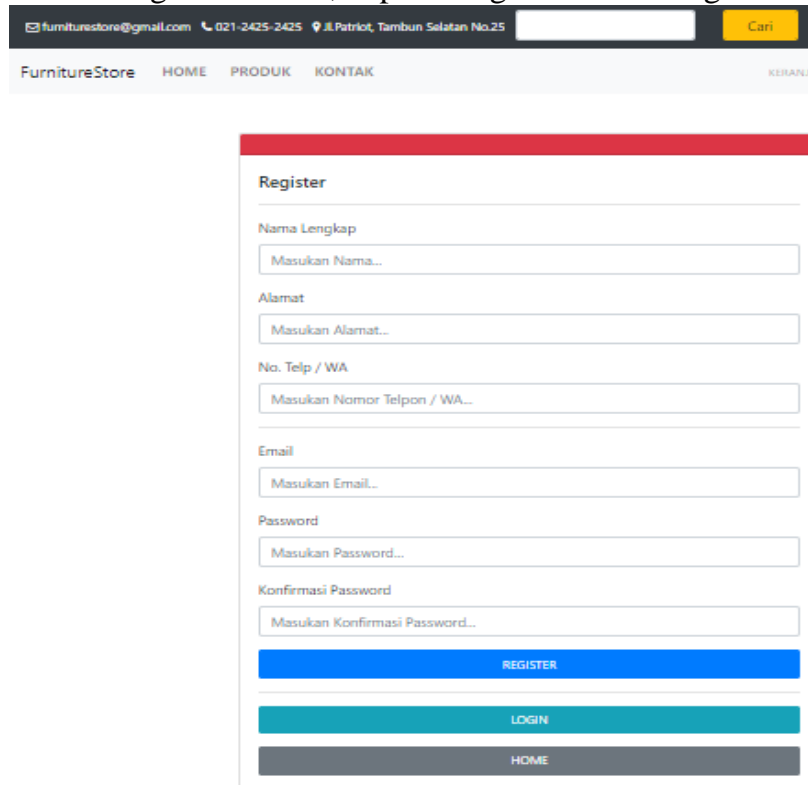

Sumber: Hendri (2021)

Gambar 6. Halaman Menu Register 
Computer Science (CO-SCIENCE)

Volume 1 No. 2 Juli 2021 | E-ISSN: 2774-9711

Menu login user untuk masuk ke halaman beranda dan melakukan transaksi.

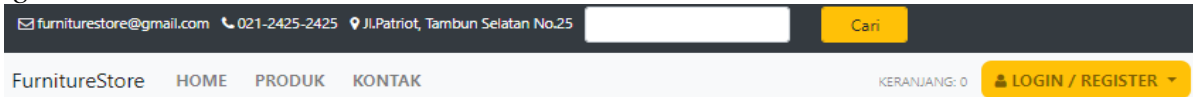

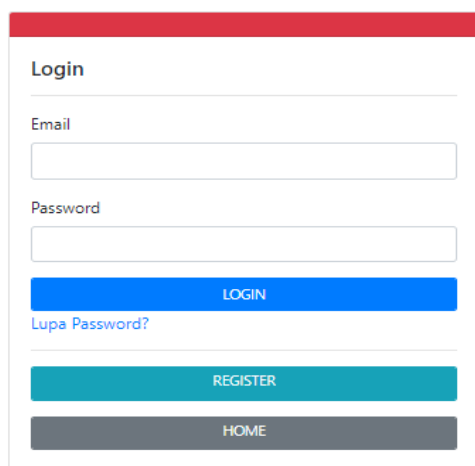

Sumber: Hendri (2021)

Gambar 7. Halaman Menu Login

Halaman utama pengunjung saat pengunjung membuka alamat website pertama kali.

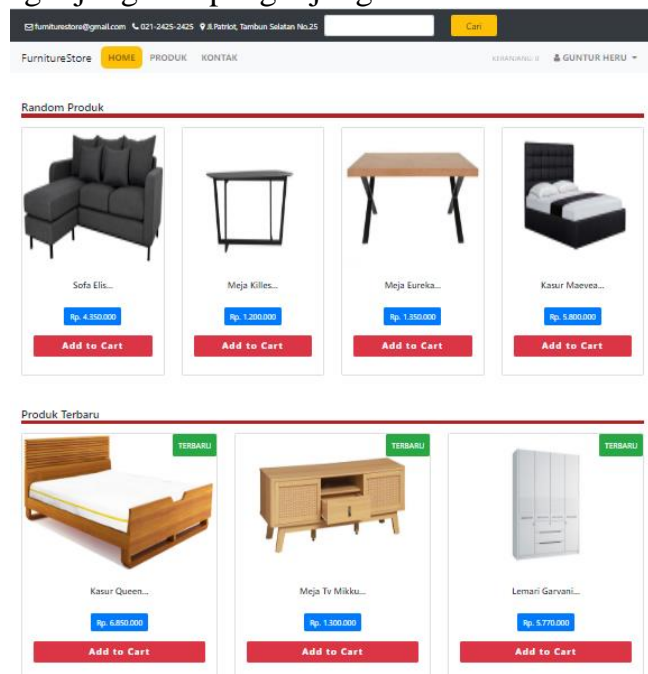

Sumber: Hendri (2021)

Gambar 8. Halaman Menu User

Halaman dashboard admin dapat mengelola sesuai kebutuhan.

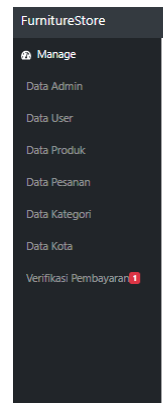

Dashboard

\section{Dashboard}

Admin

1. Admin dapat memanage datta Adm
2. Admin dapat memanage data User

Admin dapat memanange data uset
Admin dapat memangege data

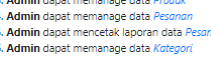

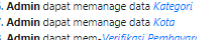

Rio Nugraha A Estproal

Alamat:

Villa 1

Teip/WA:

rio@admincon

Sumber: Hendri (2021)

Gambar 9. Menu Dashboard Admin 
Computer Science (CO-SCIENCE)

Volume 1 No. 2 Juli 2021 |E-ISSN: 2774-9711

Untuk mencetak laporan penjualan

\section{Laporan Data Pesanan 27 Juni 2020}

\begin{tabular}{|c|c|c|c|c|c|c|}
\hline No. Invoice & Nama Penerima & No Telp & Alamat & Tgl Pesan & Status & Harga \\
\hline TRAN-11747 & Refriando & 09810938102983 & Graha Prima & 27 Juni 2020 & Menunggu Pembayaran & $\operatorname{Rp.} 4,380,000$ \\
\hline TRAN-14290 & Guntur Heru & 09123123123 & Villa 1 & 27 Juni 2020 & Menunggu Pembayaran & $\operatorname{Rp} .4,380,000$ \\
\hline TRAN-71829 & Hendro & 0899887766 & Villa 1 & 27 Juni 2020 & Menunggu Pembayaran & $\operatorname{Rp.} 6,330,000$ \\
\hline TRAN-76639 & Wawan & 0123432 & Regency & 27 Juni 2020 & Menunggu Pembayaran & Rp. $5,900,000$ \\
\hline \multicolumn{6}{|l|}{ Total Harga } & Ro. $20,990,000$ \\
\hline
\end{tabular}

Sumber: Hendri (2021)

\section{Gambar 10. Menu Cetak Laporan}

Pada pembuatan Aplikasi penjualan furniture, menggunakan menggunakan framework Codeigniter dengan bahasa pemrograman HTML, PHP dan database yang digunakan yaitu MySQL.

Pada Penelitian ini dilakukan pengujian menggunakan black box testing untuk memastikan apakah aplikasi yang dihasilkan sudah sesuai dengan rancangan yang dibuat. Pengujian yang dilakukan berfokus pada persyaratan fungsional perangkat lunak. Pengujian ini bertujuan untuk menunjukkan cara operasi fungsi perangkat lunak dan untuk mengetahui apakah data masukan dan keluaran sudah sesuai dengan yang diharapkan.

Tabel 1. Hasil Pengujian Black Box Testing Terhadap Form Register User

\begin{tabular}{|c|c|c|c|c|c|}
\hline No & Skenario Pengujian & Test Case & $\begin{array}{c}\text { Hasil yang } \\
\text { Diharapkan }\end{array}$ & $\begin{array}{c}\text { Hasil } \\
\text { Pengujian }\end{array}$ & Kesimpulan \\
\hline 1 & $\begin{array}{l}\text { Nama, Alamat, No Telp, } \\
\text { Email, Password, } \\
\text { Konfirmasi Password } \\
\text { dan kemudian klik } \\
\text { Register }\end{array}$ & $\begin{array}{l}\text { Nama } \\
\text { (kosong) } \\
\text { Alamat } \\
\text { (kosong) } \\
\text { No Telp } \\
\text { (Kosong) } \\
\text { Email } \\
\text { (kosong) } \\
\text { Password } \\
\text { (kosong) } \\
\text { Konfirmasi Password } \\
\text { (kosong) }\end{array}$ & $\begin{array}{l}\text { Sistem akan } \\
\text { menolak untuk } \\
\text { Register dan } \\
\text { menampilkan pesan } \\
\text { "Data Tidak Boleh } \\
\text { Kosong" }\end{array}$ & Sesuai harapan & Valid \\
\hline 2 & $\begin{array}{l}\text { Nama, Alamat, No Telp, } \\
\text { Email, Password, } \\
\text { Konfirmasi Password } \\
\text { dan kemudian klik } \\
\text { Register }\end{array}$ & $\begin{array}{l}\text { Nama: } \\
\text { (Benar) } \\
\text { Alamat (kosong) } \\
\text { No Telp } \\
\text { (kosong) } \\
\text { Email } \\
\text { (kosong) } \\
\text { Password } \\
\text { (kosong) } \\
\text { Konfirmasi Password } \\
\text { (kosong) }\end{array}$ & $\begin{array}{l}\text { Sistem akan } \\
\text { menolak untuk } \\
\text { Register dan } \\
\text { menampilkan pesan } \\
\text { "Alamat tidak boleh } \\
\text { kosong" }\end{array}$ & $\begin{array}{l}\text { Sesuai } \\
\text { Harapan }\end{array}$ & Valid \\
\hline 3 & $\begin{array}{l}\text { Nama, Alamat, No Telp, } \\
\text { Email, Password, } \\
\text { Konfirmasi Password } \\
\text { dan kemudian klik } \\
\text { Register }\end{array}$ & $\begin{array}{l}\text { Nama : } \\
\text { (Benar) } \\
\text { Alamat : (Benar) } \\
\text { No Telp } \\
\text { (Kosong) } \\
\text { Email } \\
\text { (kosong) } \\
\text { Password } \\
\text { (kosong) } \\
\text { Konfirmasi Password } \\
\text { (kosong) }\end{array}$ & $\begin{array}{l}\text { Sistem akan } \\
\text { menolak } \\
\text { untuk Register dan } \\
\text { menampilkan pesan } \\
\text { "No Telp tidak boleh } \\
\text { kosong" }\end{array}$ & Sesuai harapan & Valid \\
\hline
\end{tabular}


Computer Science (CO-SCIENCE)

Volume 1 No. 2 Juli 2021 | E-ISSN: 2774-9711

\begin{tabular}{|c|c|c|c|c|c|}
\hline No & Skenario Pengujian & Test Case & $\begin{array}{c}\text { Hasil yang } \\
\text { Diharapkan }\end{array}$ & $\begin{array}{c}\text { Hasil } \\
\text { Pengujian }\end{array}$ & Kesimpulan \\
\hline 4 & $\begin{array}{l}\text { Nama, Alamat, No Telp, } \\
\text { Email, Password, } \\
\text { Konfirmasi Password } \\
\text { dan kemudian klik } \\
\text { Register }\end{array}$ & 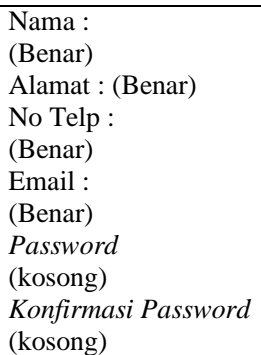 & $\begin{array}{l}\text { Sistem akan } \\
\text { menolak } \\
\text { untuk Register dan } \\
\text { menampilkan pesan } \\
\text { "Password tidak } \\
\text { boleh kosong" }\end{array}$ & Sesuai harapan & Valid \\
\hline 5 & $\begin{array}{l}\text { Nama, Alamat, No Telp, } \\
\text { Email, Password, } \\
\text { Konfirmasi Password } \\
\text { dan kemudian klik } \\
\text { Register }\end{array}$ & $\begin{array}{l}\text { Nama : } \\
\text { (Benar) } \\
\text { Alamat : (Benar) } \\
\text { No Telp : } \\
\text { (Benar } \\
\text { Email } \\
\text { (Benar) } \\
\text { Password } \\
\text { (Benar) } \\
\text { Konfirmasi Password } \\
\text { (kosong) }\end{array}$ & $\begin{array}{lr}\text { Sistem akan } \\
\text { menolak } \\
\text { untuk Register dan } \\
\text { menampilkan pesan } \\
\text { "Password tidak } \\
\text { cocok } & \text { dengan } \\
\text { konfirmasi } & \\
\text { password" } & \end{array}$ & Sesuai harapan & Valid \\
\hline 6 & $\begin{array}{l}\text { Nama, Alamat, No Telp, } \\
\text { Email, Password, } \\
\text { Konfirmasi Password } \\
\text { dan kemudian klik } \\
\text { Register }\end{array}$ & $\begin{array}{l}\text { Nama : } \\
\text { (Benar) } \\
\text { Alamat : (Benar) } \\
\text { No Telp : } \\
\text { (Benar) } \\
\text { Email : } \\
\text { (Benar) } \\
\text { Password } \\
\text { (Benar) } \\
\text { Konfirmasi Password } \\
\text { (Benar) }\end{array}$ & $\begin{array}{l}\text { Sistem menerima } \\
\text { data Register, } \\
\text { kemudian langsung } \\
\text { dialihkan ke } \\
\text { halaman Login dan } \\
\text { menampilkan pesan } \\
\text { "Berhasil melakukan } \\
\text { register" }\end{array}$ & Sesuai harapan & Valid \\
\hline
\end{tabular}

Sumber: Hendri (2021)

Tabel 2. Hasil Pengujian Black Box Testing halaman Form data Pembayaran

\begin{tabular}{|c|c|c|c|c|c|}
\hline No & Skenario Pengujian & Test Case & $\begin{array}{c}\text { Hasil yang } \\
\text { Diharapkan }\end{array}$ & $\begin{array}{c}\text { Hasil } \\
\text { Pengujian }\end{array}$ & Kesimpulan \\
\hline 1 & $\begin{array}{lrr}\text { Nama } & \text { Penerima,No } & \text { Telp, } \\
\text { Alamat, } & \text { Kota, } & \text { Jasa } \\
\text { Pengiriman, Bank } & \text { Payment } \\
\text { dan kemudian klik } & \text { Selesai } \\
\text { Belanja } & & \end{array}$ & $\begin{array}{l}\text { Nama Penerima: } \\
\text { (kosong) } \\
\text { No Telp: } \\
\text { (kosong) } \\
\text { Alamat: } \\
\text { (Kosong) } \\
\text { Kota:(Benar) } \\
\text { Jasa Pengiriman: } \\
\text { (Benar) } \\
\text { Bank Payment: } \\
\text { (Benar) }\end{array}$ & $\begin{array}{lr}\text { Sistem akan } \\
\text { menolak untuk } \\
\text { selesai belanja dan } \\
\text { menampilkan "Data } \\
\text { Tidak } \\
\text { Kosong" }\end{array}$ & Sesuai harapan & Valid \\
\hline 2 & 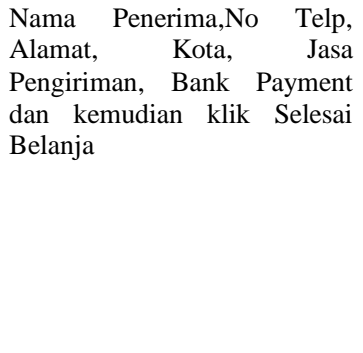 & $\begin{array}{l}\text { Nama Penerima: } \\
\text { (Benar) } \\
\text { No Telp: } \\
\text { (kosong) } \\
\text { Alamat: } \\
\text { (Kosong) } \\
\text { Kota:(Benar) } \\
\text { Jasa Pengiriman: } \\
\text { (Benar) } \\
\text { Bank Payment: } \\
\text { (Benar) }\end{array}$ & $\begin{array}{l}\text { Sistem akan } \\
\text { menolak untuk } \\
\text { selesai belanja dan } \\
\text { menampilkan "Data } \\
\text { tidak boleh kosong" }\end{array}$ & $\begin{array}{l}\text { Sesuai } \\
\text { Harapan }\end{array}$ & Valid \\
\hline 3 & $\begin{array}{l}\text { Nama Penerima,No } r \text { Telp, } \\
\text { Alamat, Kota, } \\
\text { Pengiriman, Bank } \\
\text { dan kemudian klik } \\
\text { Belanja }\end{array}$ & $\begin{array}{l}\text { Nama Penerima: } \\
\text { (Benar) } \\
\text { No Telp: } \\
\text { (Benar) } \\
\text { Alamat: } \\
\text { (Kosong) } \\
\text { Kota:(Benar) } \\
\text { Jasa Pengiriman: } \\
\text { (Benar) } \\
\text { Bank Payment: } \\
\text { (Benar) }\end{array}$ & $\begin{array}{l}\text { Sistem akan } \\
\text { menolak untuk } \\
\text { selesai belanja dan } \\
\text { menampilkan "Data } \\
\text { tidak boleh kosong" }\end{array}$ & Sesuai harapan & Valid \\
\hline
\end{tabular}


Computer Science (CO-SCIENCE)

Volume 1 No. 2 Juli 2021 | E-ISSN: 2774-9711

\begin{tabular}{|c|c|c|c|c|c|}
\hline No & Skenario Pengujian & Test Case & $\begin{array}{c}\text { Hasil yang } \\
\text { Diharapkan } \\
\end{array}$ & $\begin{array}{c}\text { Hasil } \\
\text { Pengujian }\end{array}$ & Kesimpulan \\
\hline 4 & $\begin{array}{lrr}\text { Nama } & \text { Penerima,No } & \text { Telp, } \\
\text { Alamat, } & \text { Kota, } & \text { Jasa } \\
\text { Pengiriman, Bank } & \text { Payment } \\
\text { dan kemudian } & \text { klik } & \text { Selesai } \\
\text { Belanja } & & \\
& \end{array}$ & $\begin{array}{l}\text { Nama Penerima: isi } \\
\text { (Benar) } \\
\text { No Telp: } \\
\text { (Benar) } \\
\text { Alamat: } \\
\text { (Benar) } \\
\text { Kota:(Benar) } \\
\text { Jasa Pengiriman: } \\
\text { (Benar) } \\
\text { Bank Payment: } \\
\text { (Benar) }\end{array}$ & $\begin{array}{l}\text { Sistem menerima } \\
\text { data Pembayaran, } \\
\text { kemudian langsung } \\
\text { dialihkan ke } \\
\text { halaman Invoice dan } \\
\text { menampilkan detail } \\
\text { Invoice }\end{array}$ & Sesuai harapan & Valid \\
\hline
\end{tabular}

Sumber: Hendri (2021)

Tabel 3. Hasil Pengujian Black Box Testing halaman Form Konfirmasi Pembayaran

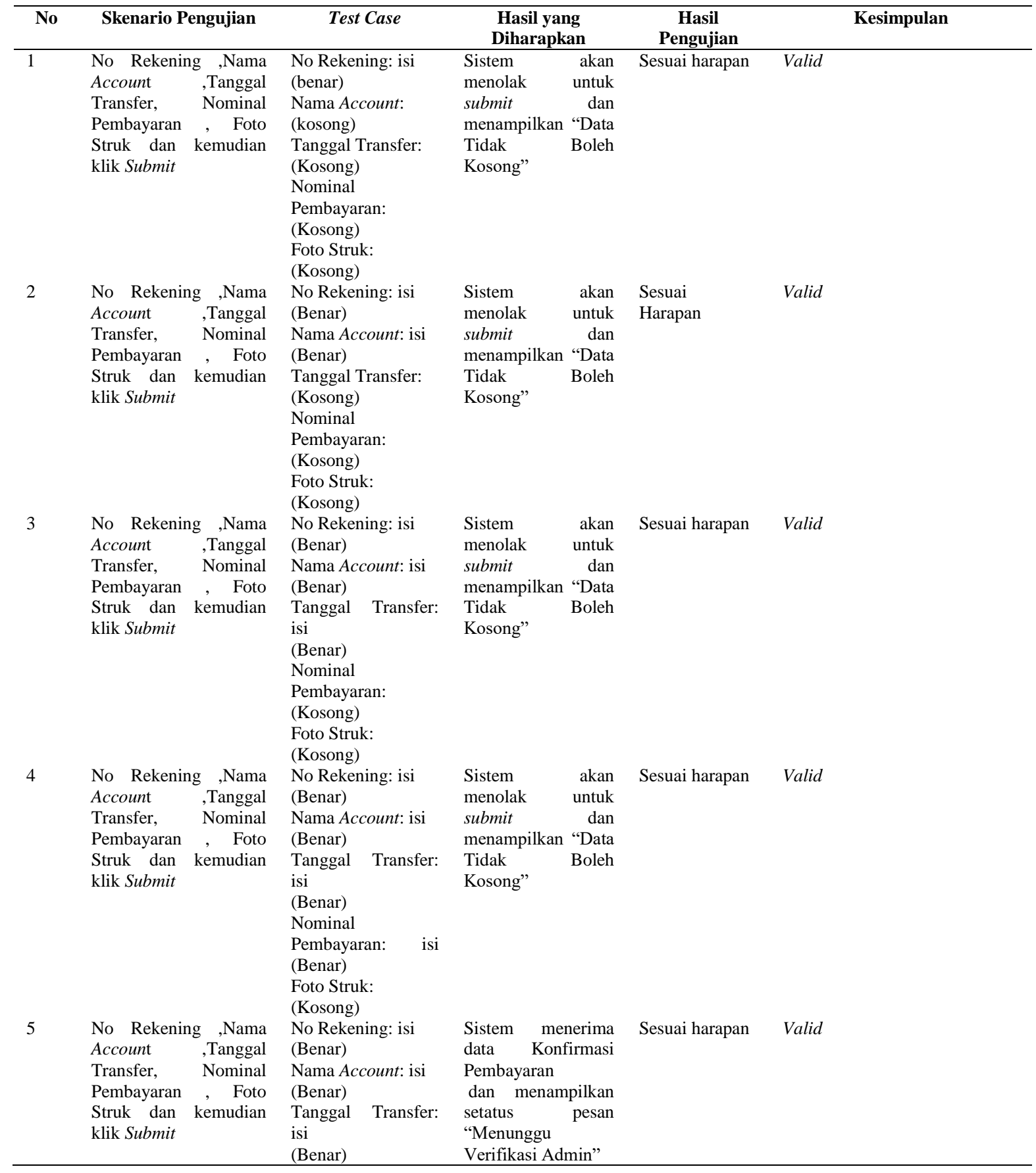




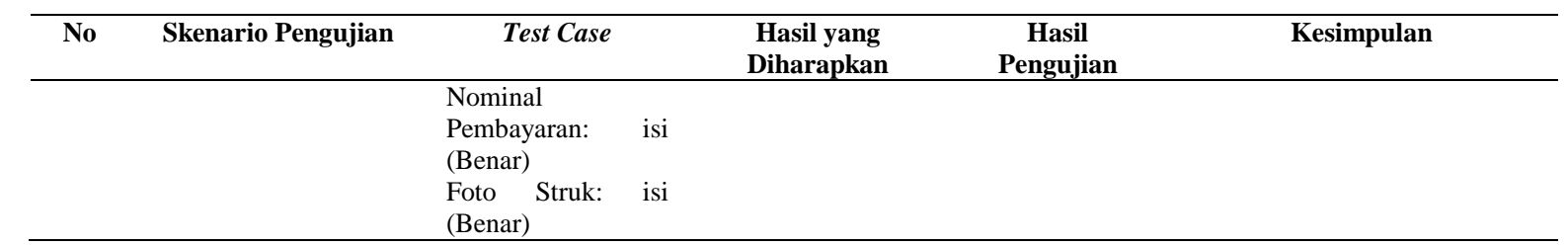

Sumber: Hendri (2021)

\section{KESIMPULAN}

Berdasarkan pada hasil penelitian dan pengujian yang telah dilakukan, dapat disimpulkan bahwa aplikasi penjualan furniture dengan metode waterfall berbasis web dapat mengatasi permasalahan yang ada kini Toko Depo furniture mempublikasikan informasi dan penawarkan produk secara online kepada masyarakat luas, penjualan produk kini dapat dilakukan secara online dengan setiap proses yang saling terintegrasi menghasilkan laporan perhitungan penjualan yang cepat, tepat dan akurat.

Dengan sifat metode waterfall yang sistematis dan berurutan dalam membangun sebuah perangkat lunak memudahkan peneliti dalam memahami dan menerapkan dalam proses pembuatan aplikasi penjualan furniture berbasis web.

Pada aplikasi penjualan furniture dengan metode waterfall berbasis web dapat melakukan transaksi penjualan online dengan melakukan register user terlebih dahulu sebelum nentinya dapat login kedalam aplikasi.

\section{REFERENSI}

Danuri, M. (2019). PERKEMBANGAN DAN TRANSFORMASI. INFOKAM, 116-123.

Ermawati, E., Ichsan, N., \& Wahyuni, T. (2018). Sistem Informasi Penjualan Furniture Berbasis Web. Jurnal Interkom, 13(3), 41-47.

Fandhilah, Pratmanto, D., \& Fatakhudin, A. (2015). Rancang Bangun Sistem Informasi Pemesanan Paket Pernikahan Dan Preweding Berbasis Web ISSN : 2461-0690 ISSN : 2461-0690. Indonesian Journal On Software Engineering Rancang, 1-9.

Hamdan. (2018). INDUSTRI 4.0: PENGARUH REVOLUSI INDUSTRI PADA KEWIRAUSAHAAN DEMI KEMANDIRIAN EKONOMI. Jurnal Nusamba, 3(2), 1-8. Https://Doi.Org/10.29407/Nusamba.V3i2.12142

Irawan, Y., Rahmalisa, U., Wahyuni, R., \& Devis, Y. (2019). Sistem Informasi Penjualan Furniture Pada CV . Satria Hendra Jaya Pekanbaru Berbasis Web ( Sales Information Systems Furniture In CV . Satria Hendra Jaya Pekanbaru Based On Web ), 1(2), 150-159.

Muhammad, \& Kusnadi, Y. (2018). APLIKASI SISTEM INFORMASI PEMESANAN PAKET PERNIKAHAN BERBASIS WEB ( Studi Kasus : SANGGAR LARAS WEDDING BOGOR ). Jurnal Teknologi Informatika \& Komputer, 4(2), 19-24.

Prasetyo, A., \& Susanti, R. (2016). Sistem Informasi Penjualan Berbasis Web Pada PT . Cahaya Sejahtera Sentosa Blitar, 10(2), 1-16.

Rahmayu, M. (2016). Rancang Bangun Sistem Informasi Pada Rumah Sakit Dengan Layanan Intranet Menggunakan Metode Waterfall Mulia. Evolusi, 4(2), 33-40.

Saryoko, A., Studi, P., Komputer, T., Labu, P., \& Selatan, J. (2015). PERANCANGAN SISTEM INFORMASI PENJUALAN FURNITURE BERBASIS WEB PADA PK . BUMI JAYA BEKASI, XIII(1), 9-19.

Susanto, R., Andriana, A. D., Susanto, R., \& Andriana, A. D. (2016). Perbandingan Model Waterfall Dan Prototyping. Majalah Ilmiah UNIKOM, 41-46. 